\title{
Low Back Pain Prevalence in Brazilian Helicopter Pilots
}

\begin{abstract}
Gillvan V da Silva*
Operational Human Performance Graduate Program, The Brazilian Air Force University, Brazil Department of Environmental Medicine, Program of Ergonomics and Biomechanics, New York University, New York
\end{abstract}

*Corresponding author: Gilvan V. da Silva, Operational Human Performance Graduate Program, The Brazilian Air Force, University, Av. Mal. Fontenelle, 1000, Rio de Janeiro-RJ 21740-002, Brazil, Email: gvs219@nyu.edu

\section{Research Article}

Volume 4 Issue 3

Received Date: May 19, 2020

Published Date: June 08, 2020

DOI: $10.23880 /$ eoij-16000240

\section{Abstract}

Studies have suggested a higher prevalence of low back pain in helicopter pilots when compared to the general population. This work aims to study the frequency distribution of recurrent low back pain observed in civilian and military helicopter pilots. To carry out the survey, a self-reported questionnaire was applied to 197 helicopter pilots, of which 106 were military personnel and 91 were civilians. The questionnaire was the same used by da Silva 2018 and Bongers et al. 1990. The data collected were: age, weight, height, total flight hours in rotary-wing aircraft, average hours flown per week, level of Physical activity, characteristics, intensity and region of pain, its relationship with flight, etc. Of the 197 tabulated questionnaires, the prevalence of low back pain of $44.6 \%$ and spinal pain of $54.2 \%$ were found, and of this group, $98.15 \%$ reported pain during or immediately after the flight, and only less than $2.0 \%$ affirms that the referred pain has no connection with air activity. These data confirm those found in the literature. The present study is part of an investigation process that, through the analysis and interpretation of the collected data, aims to provide subsidies for a future elaboration of a specific physical exercise program for the reduction of low back pain in helicopter pilots.

Keywords: Back Pain; Spinal Pain; Helicopter Pilots

\section{Introduction}

Low back pain (LBP) is one of the most common diseases in the western world, affecting approximately 60 to $85 \%$ of the population at some point in their life with a LBP prevalence of $23 \%$. Non-specific low back pain is considered worldwide health issue as the leading cause of functional disability [1-3]. Its socio-economic influence is vast, being one of the main causes of absenteeism from work and even leading to early retirement. Disability resulting from lumbar spine pain is more common than any other cause of limiting professional activity in adults under the age of [3-5].

Studies have suggested a higher prevalence of low back pain in helicopter pilots (HP) when compared to the general population in which the prevalence of spinal pain (SP) in HP ranges from 21 to $95 \%$ and the prevalence of low back pain in helicopter pilots during the flight varies from 40 to $100 \%$. This rises a flag to flight safety, since the pain can deconcentrate the pilot, putting human lives in danger and even causing an accident [6-17].

One of the most cited primary factor that predisposes helicopter pilots to LBP is the awkward posture adopted by them during the flight $[6,10,13,17-19]$. To keep the aircraft under control, depending on the layout of the control commands, they should to adopt a posture that is bent forward, with a slight lateral inclination and trunk rotation to the left. This awkward, prolonged, and static position requires a high effort from the paravertebral musculature [7- 
10,20-23] Along with the described poor posture, the whole body vibration (WBV) which helicopter pilots are submitted during flight has been considered one of the most important causes for the LBP onset. Byeon et al 2013 study indicates that WBV, along with other factors like accumulated flight hours, age and longtime flights, is related to degenerative changes of the lumbar spine in helicopter pilots [21,22]. Similarly, the increased total flying hours as well as age, sedentary life style, smoking habits, and impaired back muscle endurance has been suggested as LBP predictors for helicopter pilots [23].

The main features of the low back pain in HP can be summarized as follows: it is non-irradiating and temporary pain (lasts only a few hours) that manifests itself in a diffuse manner in the lower back region accompanied by a feeling of tiredness that normally appears during or immediately after the flight and that only it manifests after some time from the beginning of air activity, which characterizes it as recurrent/transient pain $[6,10,13,18-20]$. The time of onset of transient pain depends on the pilot, the helicopter, the type of mission and the total hours flown since complaints of transient pain start to be reported by the HP between 300 and 1500 flight hours, that is, in pilots with a certain experience. However, the literature also recorded pilots who experienced recurrent low back pain before the first 100 hours of flight. Likewise, chronic pain (lasting several days) is that pain that normally radiates to the legs, which requires absolute rest or temporarily incapacitates for flight or needs medical treatment and persists for several days, compared to idiopathic low back pain that affects the general population, also affects PH. Its prevalence increases over time and usually appears only after 2000 hours of flight $[7,8,11,16,17]$.

In this scope, epidemiological studies have divided HPs suffering from LBP into two distinct populations considering the pain pattern; a very small one, around $11 \%$, which is formed by crew members suffering from chronic low back pain, which is not directly associated with flight and a much larger one, around $73 \%$, composed of crew members who experience recurrent low back pain, that is, one that appears during or immediately after the flight and disappears after a few hours of rest $[6,17]$.

Due to the facility to recruit and to control the subjects as well as for the intrinsic homogeneity, most LBP studies with HP are conducted with military pilots lasting few data about the impact of LBP in helicopter civilian pilots [9]. In a previous study with 207 commercial helicopter pilots the prevalence of transient LBP related to flying was found as $50 \%$ and the back pain reported was $67 \%$ [6]. In another study comparing military $(n=78)$ and civilian $(n=52)$ rotatory wing pilots were found higher prevalence values for both population as $83 \%$ and $81 \%$ regarding the spinal pain and $75 \%$ and $78 \%$ for LBP, respectively. Considering the pain pattern classification, the military pilot presented $65 \%$ of transient pain related to flight and $32 \%$ of chronic pain, which was very like civilian pilots with $62 \%$ of transient and $37 \%$ of chronic. No statically significant difference was found between these studied populations [9].

Low back pain in helicopter pilots can be caused either by factors existing in the cabin's internal environment, or by factors arising from the behavior and lifestyle of this population. In a review on this subject, several researchers [6-17] have pointed out the following causes as being the main causes: the posture adopted by the pilot in the seated position during the flight, ergonomic issues in the cockpit; the vibration transmitted by the seat, the weak back muscles, sedentary life style and other individual characteristics.

Da Silva [10] in his analysis found the following etiological factors asymmetrical in-flight posture; cockpit design/ geometry; seat design; WBV; static posture; prolonged sitting; and flight duration as mainly risk factors.

The objectives of this work are to provide the prevalence of low back pain in Brazilian, civilian and military helicopter pilots, through the study of the frequency distribution, test possible associations between pain and suspected predictors. The knowledge of the frequency and distribution of an event, in the form of prevalence, informs the magnitude and the importance of the damage to the population's health, as well as it is also the most indicated form when it is intended to place the population a treatment program [24].

\section{Material and Methods}

Data collection was carried out through a selfadministered questionnaire in 197 helicopter pilots, of which 106 were military and 91 were civilians. It is noteworthy that, before starting their aerial activities, both military and civilian pilots undergo identical medical examinations and annually they carry out the same periodic medical examinations.

The questionnaire applied was was the same used by da Silva [10] and in three studies carried out in the Netherlands, about the effect of helicopter flight on pilots' health. The data collected in the questionnaire were: age, weight, height, total hours of flight in rotary wing aircraft, average hours flown per week, level of physical activity, characteristic, intensity and region of pain, its relationship with flight, etc.

From the questions about the need for medical treatment, duration, pattern and irradiation of pain and based on the 
definitions cited in the literature, it was possible to classify the reported pain into chronic and recurrent. In addition, there was also a question that allowed to verify whether the prevalence of pain was directly associated with flight.

At the bottom of each questionnaires, a small text was placed explaining the purpose of the study and the commitment to data confidentiality and requesting the collaboration of the pilots. In addition, the fact that the questionnaires were anonymous, served as a strategy for obtaining more reliable responses, since most pilots were concerned with the possibility of being grounded for medical treatment. Most of the questionnaires were distributed and collected by trusted people belonging to the staff of the collection sites (squadrons or companies), and the others were sent by e-mail.

In order to better characterize the studied population, the descriptive statistics as average data of the respective variables with their respective standard deviatio, as well as the frequency, were used. For prevalence comparison between military and civilian helicopter pilots, the "N-1" Chi-squared test as recommended by Campbell (2007) and Richardson (2011) for comparing proposrtions [25,26].

The Non-Parametric Chi-Square test was used as inferential statistics, to test the interdependence between the frequency distributions observed. For this, it was necessary to standardize the process of approaching the variables, through the distribution partition procedure, for the continuous content variables (Flight Hours, Practice Time, etc.). The partition method performed was the same used by da Silva [10] and Bongers, et al. [7] through which the same classes and the consequent nominal classification are constituted, allowing the crossing of distributions using the
Chi-Square as a method for dependency analysis. The level of significance used for the analysis was $p<0.05$. Statistical analysis was carried out with Minitab $®$ (version12, Minitab Inc., State College, PA) and SPSS $®$ (Released 2010. IBM SPSS Statistics Standard Grad Pack Shinkwrap, version19.0 for Windows. Armonk, NY: IBM Corp.) Software.

\section{Results}

Of the total of 258 questionnaires distributed, 201 were answered, 197 of which were used in the analysis. Four questionnaires were eliminated because they were incomplete and there was a lack of essential information to tabulate the data, resulting in a participation rate of $77.9 \%$ (Table 2).

Regarding the study population, the average age in years was $33.8 \pm 8.7$, weight $78.9 \pm 12.4$, height $1.77 \mathrm{~m} \pm 0.15$ and flight hours 1441.1 hours \pm 2113.8 . The average flying experience was 9.3 years \pm 7.1 , ranging from 6 months to 37 years. From the 106 military pilots (MP) participants, 28 were from the Brazilian Army Aviation Group (GavEx) based in Manaus-AM and 78 from the Brazilian Air Force (FAB) belonging to FAB flight squadrons based countrywide. Among the 91 civilian pilots (CP), 46 belonged to offshore helicopter companies flying at the Campos Basin and 45 belonged to the São Paulo Helicopter Pilots Union, employed by several companies in the air taxi sector. The summary statistics of the studied population is shown in Table 1.

Table 1 presents the main characteristics of the population studied through the arithmetic mean and standard deviation.

\begin{tabular}{|c|c|c|c|c|c|c|c|c|c|c|c|c|}
\hline & \multicolumn{4}{|c|}{ MP (n=106) } & \multicolumn{4}{c|}{ CP (n=91) } & \multicolumn{3}{c|}{ All Pilots (n=197) } \\
\hline Demographic & Mean & SD & Min & Max & Mean & SD & Min & Max & Mean & SD & Min & Max \\
\hline Age(years) & 31.5 & 6.2 & 21 & 51 & 36.5 & 10.3 & 20 & 61 & 33.8 & 8.7 & 20 & 61 \\
\hline Height (cm) & 178 & 13 & 160 & 192 & 176 & 8 & 155 & 196 & 177 & 15 & 155 & 196 \\
\hline Weight (Kg) & 79.25 & 13.22 & 60 & 125 & 78.45 & 11.5 & 50 & 105 & 78.9 & 12.4 & 50 & 125 \\
\hline BMI & 25.0 & 2.96 & 23.4 & 33.9 & 25.3 & 0.68 & 20.8 & 27.3 & 25.2 & 2.44 & 20.8 & 32.5 \\
\hline Flighthours & 962 & 786 & 50 & 3500 & 2431 & 3450 & 60 & 19000 & 1411 & 2113 & 50 & 19000 \\
\hline Experience (years) & 7.9 & 4.3 & 0.5 & 20 & 11.02 & 9.15 & 0.5 & 37 & 9.3 & 7.1 & 0.5 & 37 \\
\hline
\end{tabular}

Table 1: Characteristics of the studied population.

A total of 84 pilots (42.6\%) declared not to perform Physical activity, being $63 \mathrm{CP}$ and $21 \mathrm{MP}$, which represent $69.2 \%$ of CP and $19.8 \%$ of PM..
Table 2 shows theresponse rate among the questionnaires distributed, returned and analyzed. General response rate was $77.9 \%$, but when spliting into military and civilian HP the response rates are $78.3 \%$ and $88 \%$, respectively. 


\begin{tabular}{|c|c|c|c|}
\hline \multicolumn{3}{|c|}{ Questionnnaires } \\
\hline Pilots' work & Distributed & Returned (\%) & Analyzed \\
\hline MP Army & 32 & $29(90.6)$ & 78 \\
\hline MP Air Force & 120 & $80(66.7)$ & 46 \\
\hline CP Offshore & 54 & $49(90.7)$ & 45 \\
\hline CP Several & 52 & $46(88.5)$ & 197 \\
\hline Total & 258 & $201(77.9)$ & \\
\hline
\end{tabular}

Table 2: Response rate.

From the 197 questionnaires evaluated 108 HP responded feeling pain in the spine and 88 reported low back pain showing the majoraty of symptomatic pilots reporting lumbar region as painful, thus representing a prevalence of spinal pain (SP) of 54.8\% and low back pain (LBP) of $44.6 \%$. Twenty pilots $(10.15 \%)$ reported other regions of the spine in which they felt pain and $89(45.2 \%)$ responded that they did not experience any type of SP (Table 3).

\begin{tabular}{|c|c|c|}
\hline \multicolumn{2}{|c|}{ Total (n=197) } & \\
\hline Region of the pain & Freq. & Freq. \\
\hline Cervical & 10 & 5.1 \\
\hline Thoracic & 9 & 4.6 \\
\hline Lumbar* & 67 & 34 \\
\hline Cervical, Thoracic, and Lumbar* & 6 & 3.1 \\
\hline Cervical and Thoracic & 1 & 0.5 \\
\hline Cervical and Lumbar* & 7 & 3.5 \\
\hline Thoracic and Lumbar* & 8 & 4 \\
\hline Total with pain & 108 & 54.8 \\
\hline No pain & 89 & 45.2 \\
\hline
\end{tabular}

*Low back pain 88 cases (44.6\%)

Tabela 3: Spine regions that pilots reported pain.

According to the definitions of recurrent low back pain and chronic low back pain and considering the entire population of 197, the percentage of recurrent pain among Brazilain helicopter pilots was roughly $85 \%$ and for the chronic pain was $15 \%$, when taking into acoount the pain characteristics as pain irradiation to legs and the need of medical treatment (Table 4).

\begin{tabular}{|c|c|c|c|c|}
\hline \multirow{2}{*}{ Parameters evaluated } & \multicolumn{2}{|c|}{ Yes } & \multicolumn{2}{c|}{ No } \\
\cline { 2 - 5 } & Freq. & $\%$ & Freq. & 45.2 \\
\hline Presence of Spinal pain & 108 & 54.8 & 89 & 55.4 \\
\hline Presence Low back pain & 88 & 44.6 & 109 & 85.3 \\
\hline Pain irradiates to the legs** & 29 & 14.7 & 168 & 84.3 \\
\hline Received medical treatment** & 31 & 15.7 & 166 & 100 \\
\hline Have discal impairment & 0 & 0 & 197 & \\
\hline
\end{tabular}

Table 4: Pain characteristics ( $\mathrm{n}=197)$.

**related to chronic pain

Tables 5 and 6 are showing the results of transient and chronic distribution of pain based on the pain persistence/ duration and pain pattern. For the pain persistence/duration basis the prevalence of transient/recurrent and chronic pain 
were respectivey $39.1 \%$ and $15.6 \%$ related to the entire sample and $62 \%$ and $38 \%$ regarding the symptomatic pilots $(n=108)$. When focusing only on pain pattern the distribution of transient and chronic pain was $38.1 \%$ and $16.7 \%$ related to the entire sample and $69.4 \%$ and $30.6 \%$ regarding the symptomatic pilots $(n=108)$.

\begin{tabular}{|c|c|c|c|c|c|c|}
\hline \multirow[b]{2}{*}{ Pain duration } & \multicolumn{2}{|c|}{ MP $(n=106)$} & \multicolumn{2}{|c|}{$\mathrm{CP}(\mathrm{n}=91)$} & \multicolumn{2}{|c|}{ Toal $(n=197)$} \\
\hline & Freq. & $\%$ & Freq. & $\%$ & Freq. & $\%$ \\
\hline Less then one hour* & 15 & 7.6 & 8 & 4.1 & 23 & 11.7 \\
\hline Sereval hours* & 29 & 14.7 & 25 & 12.7 & 54 & 27.4 \\
\hline Several days** & 14 & 7.1 & 5 & 2.5 & 19 & 9.6 \\
\hline Several weeks** & 3 & 1.5 & 1 & 0.5 & 4 & 2.0 \\
\hline Several months** & 6 & 3.1 & 2 & 1 & 8 & 4.0 \\
\hline No pain & 39 & 19.8 & 50 & 25.4 & 89 & 45.2 \\
\hline
\end{tabular}

*related to recurrent/transient pain; ${ }^{* *}$ related to chronic pain

Table 5: Pain duration (persistency) $(n=197)$.

\begin{tabular}{|c|c|c|c|c|c|c|}
\hline \multirow[b]{2}{*}{ Pain pattern } & \multicolumn{2}{|c|}{ MP (n=106) } & \multicolumn{2}{|c|}{$C P(n=91)$} & \multicolumn{2}{|c|}{ Toal $(n=197)$} \\
\hline & Freq. & $\%$ & Freq. & $\%$ & Freq. & $\%$ \\
\hline Varies from day to day* & 50 & 25.4 & 25 & 12.7 & 75 & 38.1 \\
\hline long periods with pain alternated** & 11 & 5.6 & 14 & 7.0 & 25 & 12.6 \\
\hline Almost always present ${ }^{* *}$ & 6 & 3.1 & 2 & 1.0 & 08 & 4.1 \\
\hline No pain & 39 & 19.8 & 50 & 25.4 & 89 & 45.2 \\
\hline
\end{tabular}

*related to recurrent/transient pain **related to chronic pain

Table 6: Pain pattern $(n=197)$.

Results from both class of pilots were compared to verify whether these two population have similar prevalence and nature of back pain. Therefore, only pilots that reported spinal pain were taken into account (Table 7). A bar graph (Figure 1) was also provided to a better understanding of pilots population differences.

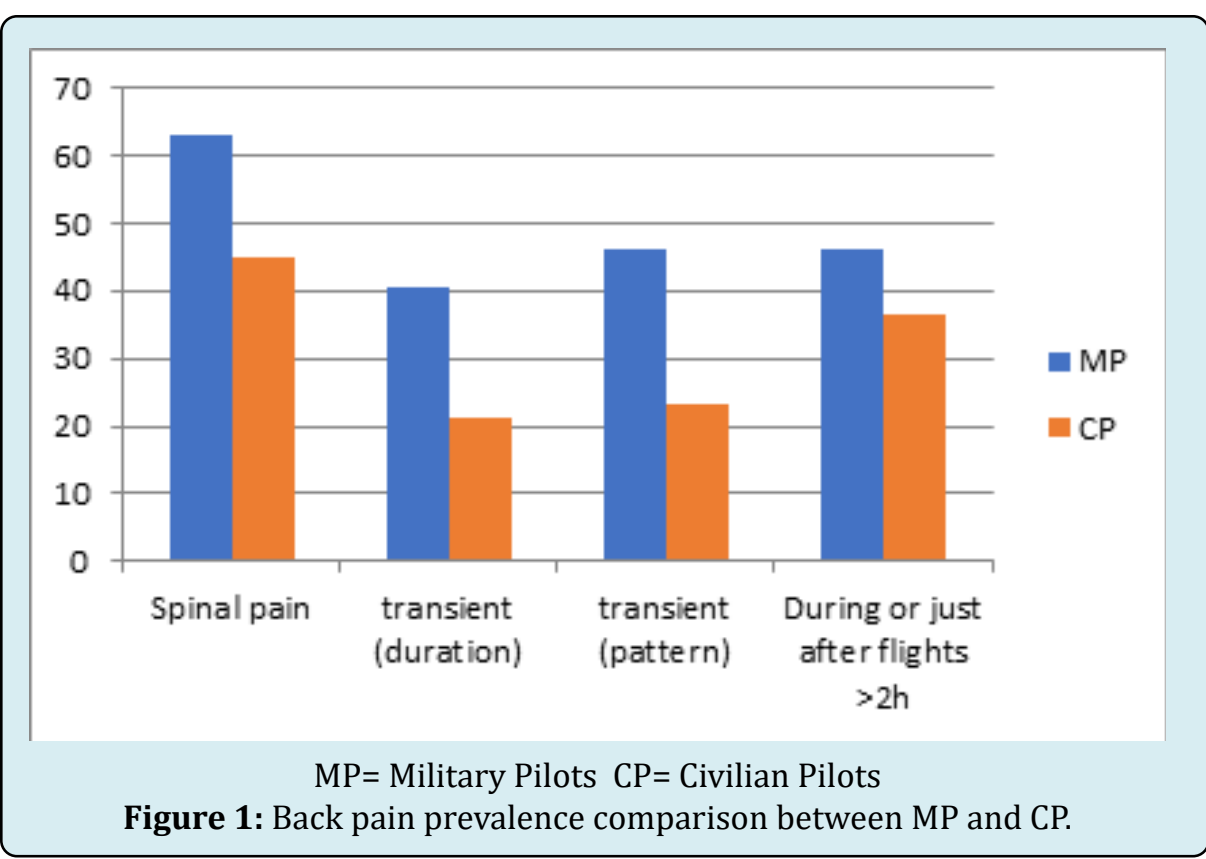




\begin{tabular}{|c|c|c|c|c|}
\hline Helicopter Pilots & \multicolumn{3}{|c|}{ Prevalence (n=108) } \\
\hline & Spinal pain & transient (duration) & transient (pattern) & During or just after flights $>2 \mathrm{~h}$ \\
\hline Military pilots (MP) & $63 \%$ & $40.7 \%$ & $46.3 \%$ & $46.3 \%$ \\
\hline Civilian pilots (CP) & $45 \%$ & $21.3 \%$ & $23.1 \%$ & $36.7 \%$ \\
\hline p-value & $\mathrm{p}=0.0158^{*}$ & $0.0388^{*}$ & $\mathrm{p}=0.0161^{*}$ & $\mathrm{p}=0.3299$ \\
\hline
\end{tabular}

*statiscally significant $(\mathrm{p}<.05)$

Table 7: Comparison between symptomatic military and civilian HP ( $\mathrm{n}=108)$.

Table 8 shows the strong association between LBP that affects HP and flight, as only two pilots declared that the pain etiology was not related to flight (one MP and one CP), which means a prevalence of $98.15 \%$ considering the $108 \mathrm{HP}$ who reported pain.

\begin{tabular}{|c|c|c|c|c|c|c|}
\hline & \multicolumn{2}{|c|}{ MP (n=106) } & \multicolumn{2}{c|}{ CP (n=91) } & \multicolumn{2}{c|}{ Total (n=197) } \\
\hline Period of pain & Freq. & $\%$ & Freq. & $\%$ & Freq. & $\%$ \\
\hline During or just after any flight & 10 & 5.1 & 8 & 4.0 & 18 & 9.1 \\
\hline During or just after flight< $2 \mathrm{~h}$ & 5 & 2.5 & 3 & 1.5 & 8 & 4.0 \\
\hline During or just after flight> 2h & 31 & 15.7 & 15 & 7.7 & 46 & 23.4 \\
\hline After flights of high concentration & 10 & 5.1 & 8 & 4.0 & 18 & 9.1 \\
\hline After periods of more than 20h/week & 10 & 5.1 & 6 & 3.1 & 16 & 8.2 \\
\hline Pain was not related to flight & 1 & 0.5 & 1 & 0.5 & 2 & 1 \\
\hline No pain & 39 & 19.8 & 50 & 25.4 & 89 & 45.2 \\
\hline
\end{tabular}

Table 8: Spinal pain prevalence directly related to flight.

Table 9 summarizes the crossings of the studied variables that were carried out in an attempt to verify an interdependence relationship between them for $p<0.05$. For this purpose, as previously mentioned, the Non-Parametric Chi-Square test was used. However, only the total amount of hours flown and the frequency reported LBP during or immediately after the flight presented dependency relationship ( $p=0.03)$, demonstrating that the amount of total hours flown interferes with transient LBP that affects helicopter pilots.
No other direct dependence relationship was found when the variables were crossed: Frequency of low back pain and Time of practice $(p=0.42)$, Frequency of low back pain and Total hours flown $(p=0.28)$, Frequency of pain low back and age $(p=0.89)$, frequency of low back pain and Physical activity $(\mathrm{p}=0.42)$, Physical activity and pattern, duration and frequency of pain during or immediately after the flight, having significance $(\mathrm{p})$ respectively with the following values: $0.89 ; 0.98$ and 0.99 .

\begin{tabular}{|c|c|c|c|}
\hline Variable 1 & Variable 2 & Chi-Square & P value \\
\hline Low back pain & Age & 27,58 & 0,89 \\
\hline Low back pain & Flight hours & 66,84 & 0,28 \\
\hline Low back pain & Physical activity & 1,72 & 0,42 \\
\hline Physical activity & Pain pattern & 2,28 & 0,89 \\
\hline Physical activity & Period of pain & 7,66 & 0,99 \\
\hline Physical activity & Pain duration & 2,94 & 0,98 \\
\hline Flight hours & Pain duration & 304,42 & 0,50 \\
\hline Flight hours & Pain pattern & 177,9 & 0,59 \\
\hline Flight hours & Period of pain & 676,21 & $\mathbf{0 , 0 3}^{*}$ \\
\hline
\end{tabular}

*statistically significant $(\mathrm{p}<.05)$

Table9: Chi-Square test results. 


\section{Discussion}

The age range, weight and heigh valuest, as well as the total hours flown, were very similar to those found and used in the literature $[6,8-10,12,13,15,17]$, which demonstrates a certain homogeneity in this study of the prevalence of low back pain in HP and the possibility of comparing the studies. Additionally, the fact that in Brazil civilian and military pilots undergo the same medical examinations also characterizes the homogeneity of the sample used, a very relevant fact when conducting an epidemiological survey $[2,5]$.

Another positive feature that allows further comparison is the use of equal definitions as important procedure, so that it is possible to know whether studies on the same subject or population can be compared and / or reproduced, hence the concern of the present study in verifying how the literature defines and divides low back pain in HP [2,5].

When considering the pilots as a single group as Brazilian HP, the prevalences of spinal pain (54.8\%), low back pain (44.6\%), pain during or immediately after flights with less than two hours (36.5\%), recurrent (85\%), and chronic pain (15\%) found in this investigation are similar to the findings in the literature [6-23]. The LBP prevalence of $44.6 \%$ is similar to the $48.1 \%$ found by Posh, et al.[15]. But when comparing the Brazilian HP between them, there are some differences. Similarly to Cunningham [9], the difference of total amount of hours of flight between military and cilvilian HP was significant.

The military helicopter pilots' prevalence of back pain is well-documented with several researches showing prevalences from $44 \%$ to $92 \%$ [10]. Conversely, just few researches are dedicated to assess back pain prevalence in rotatory wing commercial/civilian helicoptet pilots. In a study with military (RAF) and civilian pilots they showed not significant differences of SP prevalences $(83 \%$ and $81 \%$, respectively) and LBP (75\% and 78\%, respectively). Similarly, they both also showed prevalence of $62 \%$ of episodes of transient pain, just lasting few hours [9]. Another study [6] with helicopter commercial pilots found prevalence of SP of $67 \%$ and that $50 \%$ of pilots reported transient pain.

In the present study, despite of be found high prevalence values, they were below the literature when comparing by military and civilian pilots. In this way, the $45 \%$ prevalence of the spinal pain among CP was significantly different with those found in the literature of $81 \%$ and $67 \%$ [6,9]. Likewise, when the Brazilian pilots are compared between military and civilian pilots the results were not similar or homogenous like the study of Cunningham [9]. The prevalence of spinal pain in MP $(63 \%)$ was statistically significant $(\mathrm{p}<.05)$ higher than CP (45\%). Furthermore, the distribution into transient and chronic when considering the pain duration was also different statistically different $(\mathrm{p}<.05)$ with MP showing $40.7 \%$ of transient and $21.3 \%$ of chronic and CP presented $21.3 \%$ of transient and $16.7 \%$ of chronic, considering the sympotomatic HP $(\mathrm{p}<.05)$. Correspongingly, when considering the pain pattern the difference betweem MP and CP was also significantly $(\mathrm{P}<.05)$ as shown on Table 7 . This findings suggesting that in Brazil, despite of MP presented a higher prevalence of back ache, the nature of this pain less severe than that one that affect the civilian pilots, which can be explained by the higher amount of accumulated hours of flight experienced by the civilians.

The practice of general physical activites seems not to interfere in the in the low back pain etiology, which is in accordance with some studies $[6,10]$, but in disagreement with others [22,23]. However, it seems to have some influence over the morbity of the pain, being the less psysically conditioned ones more susceptible to the chronic pain. This seems to be the case with the Brasilian pilots, since among the MP sample $80.2 \%$ was physically active against only $30,8 \%$ of the CP. Apparently, the effect of have a nonsedentary life style or practice geral physical exercises has no effective result, otherwise, when using specific programas to increase the back muscles force and endurance it seems to provoke a reduction of morbidy of the pain related to its intensity, durantion or pattern helping HP to better suppor ther flight activiy $[10,15,21]$.

More than $98 \%$ of pilots that has experienced low back pain have associated it with the flight corroborating previous studies [6-23]. For the 108 pilots with pain only 2 indicated that the back pain was not related to the flight. In the same way as the literature comments, low back pain that affects HP was characterized by its recurrence and a dependency relationship ( $p<0.05)$ with the total hours flown. This finding corroborates Byeon, et al. [22] indicating that accumulated flight hours were associated with prevalence of LBP in helicopter pilots. Additionally, military and civilian pilots demonstrate significant no difference when reporting the spinal pain prevalence and its relationship with the flight (Tables 7 and 8 and Figure 1).

\section{Conclusion}

Despite the high prevalence rates of LBP in HP described in other countries, very little was known about this situation among helicopter pilots in Brazil, mainly regarding civilian pilots. In the present study, we investigated the prevalence and characteristics of pain among civilian and military HP, as well as the factors associated with it. This work is part of a broader debate, as it is part of an extensive research project about the effects of helicopter flight on the health of pilots and the development of a Physical exercise program 
as a secondary prevention factor for low back pain in this professional class.

Through the descriptive epidemiological study of low back pain in Brazilian, civilian and military helicopter pilots, it was possible to verify the magnitude of this pain in this population, as well as revealing that in general the findings of this study corroborat those reported in the literature.

The study's results pointed a significant interdependence relationship between frequency of reported LBP during or immediately after the flight and the total of accumulated flying hours. No other factors explaining spinal pain in Brazilian militay and civilian helicopter pilots was found. Thus, due to the higher prevalence of LBP among helicopter pilots as well as a significant influence of flight activity it is justified to carry out broader and more specific future studies, increasingly seeking to determine a more accurate prevalence and possible differences between militay and civilians HP, in order to support the development of primary and secondary prevention programs. aiming at the best quality of life of this class and greater safety for all those who use this means of transport, that is, not only improve lives but also save them.

The epidemiological survey on low back pain in Brazilians helicopter pilots are of great importance in revealing the proportion of HP suffering from low back pain and reinforcing the need to develop effective treatment programs with the objective of increasing the quality of life of pilots and increasing flight safety, in addition to creating physical conditions that will prevent the worsening and chronicity of low back pain resulting from pathological changes that occur over time.

\section{References}

1. Deryer SJ, Dreyfuss PH (1996) Low back pain and zigapophysal (facet) joints. Arch HPys Med Rehabil 77(3): 290-300.

2. Leboeuf C, Lauritsen M (1995) The prevalence of low back pain in literature. Spine 20(19): 2112-2118.

3. Manchikanti L, Singh V, Datta S, Cohen SP, Hirsch JA (2009) Comprehensive review of epidemiology, scope, and impact of spinal pain. Pain Physician 12(4): E35-E70.

4. Indahl A, Reikeraas O (1995) Good prognosis for low back pain when left untampered: A Randomized Clinical Trial. Spine 20(5): 473-477.

5. Loney PL, Stratford PW (1999) The prelalence of low back pain adults: a methodological review of the literature. Physical Therapy 79(4): 384-396.
6. Knut Andersen, Roald Baardsen, Harald Haga, Geir Due, Ingvild Dalen, et al. (2017) Transient Low Back Pain Among Helicopter Pilots; Imaging And Lumbar Trunk Muscular Endurance. Journal of Physical Medicine Rehabilitation \& Disabilities 3: 201.

7. Bongers PM, Hulshof CT, Dijkstra L (1990) Back pain and exposure to whole body vibration in helicopter pilots. Ergonemics 33(8): 1007-1026.

8. Bowden $\mathrm{T}$ (1987) Back pain in helicopter aircrew: a literature review. Aviation, Space and Enviromental Medicine 58(5): 461-467.

9. Laura KC, Sharon D, Alan WT (2010) Prevalence of Low Back Pain (LBP) in Rotatory Wing Aviation Pilots. Aviation, Space, and Environmental Medicine 81(8): 774-778.

10. Da Silva (2018) Helicopter Pilots and Low Back Pain: How to Manage the Risk Factors?. Ergonomics International Journal 2(1): 000130.

11. Delahaye RP (1982) The spine and fitness for flight. Physiopathology and pathology of spinal injuries in aerospace medicine. Neuilly-sur-Seine, France, AGARD, pp: 221-263.

12. Froom P, Barzilay J, Caine Y, Margaliot S, Forecast D, et al. (1986) Low back pain in helicopter pilots. Aviation, Space and Environmental Medicine 57(5): 694-695.

13. Gaydos SJ (2012) Low back pain: considerations for rotary-wing aircrew. Aviat Space Environ Med 83(9): 879-89.

14. Grant KA (2002) Ergonomic assessment of a helicopter crew seat: the HH-60G flight engineer position. Aviat Space Environ Med 73(9): 913-918.

15. Markus Posch, Alois Schranz, Manfred Lener, Werner Senn, Björn 0 Äng, et al. (2019) Prevalence and potential risk factors of flight-related neck, shoulder and low back pain among helicopter pilots and crewmembers: a questionnaire-based study. BMC Musculoskeletal Disorders 20: 44.

16. Shanahan DF (1984) Back Pain in helicopter flight operation. Aeromedical Support in Military Operations AGARD- LS 134: 9.

17. Shanahan DF (1986) Helicopter pilot back pain: a preliminary study. Aviation, Space and Eviromental Medicine 55(2): 117-121.

18. Lis AM, Black KM, Korn H, Nordin M (2007) Association between sitting and occupational LBP. Eur Spine J 16(2): 
283-298.

19. Thomae MK, Porteous JE, Brock JR, Allen GD, Heller RF (1998) Back pain in Australian military helicopter pilots: a preliminary study. Aviat Space Environ Med 69(5): 468-473.

20. Knut Andersen, Roald Baardsen, Ingvild Dalen, Jan Petter Larsen (2017) Impact of exercise programs among helicopter pilots with transient LBP. BMC Musculoskeletal Disorders 18: 269.

21. Brandt Y, Currier L, Plante TW, Schubert Kabban CM, Tvaryanas AP (2015) A randomized controlled trial of core strengthening exercises in helicopter crewmembers with low back pain. Aerosp Med Hum Perform 86(10): 889-894.
22. Joo Hyeon Byeon, Jung Won Kim, Ho Joong Jeong, Young Joo Sim, Dong Kyu Kim, et al. (2013) Degenerative Changes of Spine in Helicopter Pilots. Ann Rehabil Med 37(5): 706-712.

23. Özge Çınar-Medeni, Nevin Atalay Guzel, Murat Erdogan (2015) The Predictors of Low Back Pain in Helicopter Pilots. Gazi Medical Journal 26(1): 15-18.

24. Pereira MG (2000) Epidemiologia teoria e prática. Rio de Janeiro, Guanabara Koogan.

25. Campbell I (2007) Chi-squared and Fisher-Irwin tests of two-by-two tables with small sample recommendations. Statistics in Medicine 26(19): 3661-3675.

26. Richardson JTE (2011) The analysis of $2 \times 2$ contingency tables - Yet again. Statistics in Medicine 30(8): 890. 